\title{
Chloride diffusion analysis of reinforced concrete beam enhanced with externally bonded fibre reinforced polymer considering the presence of rebars and stirrups
}

\author{
Weilai Yao, Shiyong Jiang*, Shuai Tao, Wei Fei \\ Department of Military Infrastructure Engineering, Army Logistics University of PLA, Chongqing 401311, China
}

Corresponding Author Email: jiangshiy@163.com

https://doi.org/10.18280/ijht.360228

Received: 16 September 2017

Accepted: 21 February 2018

\section{Keywords:}

externally bonded fibre reinforced polymer (EBFRP), enhanced reinforced concrete $(R C)$ beam, chloride diffusion, longitudinal bars, stirrups

\begin{abstract}
This paper aims to realize a full scale modelling of reinforced concrete (RC) beam enhanced by externally bonded fibre reinforced polymer (EBRFP), considering both longitudinal bars and stirrups. To this end, several previous revisions to Fick's second law of diffusion were incorporated to establish a revised diffusion model. During the modelling, the following factors were taken into account simultaneously: time-dependent diffusion coefficient, timedependent surface chloride ion content, chloride binding effect, material inhomogeneity and load effect. Then, the boundary conditions were properly changed to fit the enhancement behaviour. Later, the revised diffusion model was numerically solved by the FEA on Abaqus, aiming to reveal the effect of enhancement on chloride diffusion, the effect of longitudinal bars and stirrups on chloride diffusion, and the results and efficiencies of 2D and 3D models. Through the analysis of simulation results, the author drew the following conditions: First, the EBRFP enhancement led to an obvious decrease of chloride ion content, thus extending the initial time of rebar corrosion; Second, the longitudinal rebars greatly boosted the chloride ion content at the front faces of rebars, while the effect of stirrups can be neglected if the longitudinal rebars have been considered; Third, 2D model is more recommended than 3D model if the surface chloride ion content remains invariant along the RC beam.
\end{abstract}

\section{INTRODUCTION}

In recent years, externally bonded fibre reinforced polymer (EBFRP) has been widely adopted to enhance concrete structures, thanks to the high performance of composite materials [1-2]. Nevertheless, the enhanced structures still face the problem of corrosion amidst the service environment. In marine or de-icing environment, the reinforced concrete (RC) structures mainly suffer from chloride-induced rebar corrosion [3-4]. In general, the structural deterioration under chloride ingress evolves through two stages [5]: rebar depassivation (initiation) and rebar corrosion (propagation). Traditionally, the service life depends on the initiation time $\left(T_{\mathrm{i}}\right)$, which is computed based on the chloride diffusion rate and the critical chloride content $\left(C_{\mathrm{th}}\right)$ that initiates corrosion. To predict and prolong the service life of EBFRP-enhanced RC structures, it is necessary to identify the features of chloride ingress in the enhanced structures, which are different from that in unenhanced RC structures. Nevertheless, the existing studies on chloride ingress, ranging from field test, lab experiment to theoretical analysis, mainly concentrate on unenhanced structures. There is almost no report on chloride ingress in enhanced RC structures.

In an EBFRP-enhanced RC structure, the diffusion pathways of chloride ions are partially blocked by the bonding material. Moreover, the stress within concrete member is redistributed and partly relieved through the enhancement, leading to the closure of micro cracks and slowdown of chloride diffusion. Specifically, the rebar acts as a barrier to chloride diffusion, pushing up the chloride content on its front face [6-7]. As a result, it takes a much shorter time for the chloride to reach the critical content that initiates steel corrosion. This effect of rebar on chloride ingress has been reported before. Hansen [8] was the first to point out the effect after noting the higher chloride content on the front face of the rebar than that in unenhanced positions of the same depth. Wang and $\mathrm{Li}$ [9] conducted experiments and finite-element analysis on the impact of rebar presence on chloride diffusion; the results show that chloride tends to accumulate at the apex of rebar, and that chloride content escalated more quickly with the increase of rebar diameter. Oh and Jang [10] found that the corrosion initiation time dropped by $30 \sim 40 \%$ after the addition of rebar, an evidence to the chloride accumulation at the apex of rebar. Kranc [11] and Wang [12] argued that the effect of rebar is nonnegligible in the calculation of chloride ion distribution in $\mathrm{RC}$ concrete. Comparing the results of a 1D model and a 2D model, $\mathrm{Yu}[6-7,13]$ concluded that the rebar with a big size, a thin cover and a flat front face can accelerate chloride accumualtion and reduce the initiation time. In summary, most of the above studies failed to build full-scale models for the discussion on chloride ingress in RC structures; the few studies that created full-scale models took no account of stirrups. Owing to the high modelling complexity and computing cost, the existing models for chloride ingress are one- or two-dimensional rather than three-dimensional. Of course, even 3D models require further improvement to accurately reflect the actual situations.

In addition, the previous research has revised the Fick's second law of diffusion [14-15], a well-received theory on chloride ingress in concrete. For instance, References [16-18] put forward the time-dependent diffusion coefficient for chloride ingress. References [19-20] describe the time-varying 
chloride ion content on concrete surface by linear function, power function and exponential function. To make the chloride diffusion analysis more realistic, Nillson [21] defined the binding capacity of chloride, and developed several modified diffusion models. References [22 28] demonstrate that chloride ion accumulation is accelerated by external load. These revisions are incorporated in this research to build a rigorous and comprehensive model for chloride diffusion.

In light of the above, this paper aims to build a rigorous and comprehensive model for chloride ingress considering the time-dependence of diffusion coefficient, the timedependence of surface chloride ion content, the binding capacity of chloride, the inhomogeneity of material and the effect of external load. To this end, the chloride diffusion in EBFRP-enhanced RC beam was simulated to reveal the effect of enhancement on chloride diffusion, the impacts of both longitudinal bars and stirrups on chloride ingress were discussed using full-scale model for realistically enhanced RC beam, and 2D and 3D diffusion models were compared in terms of modelling results and computing costs.

\section{REVISED DIFFUSION MODEL}

\subsection{General diffusion equation}

The target EBFRP-enhanced RC beams reside in marine environment, where chloride ingress is the leading factor affecting the beam durability. As the environment is humid all year around, the relative humidity inside the concrete is assumed to be $100 \%$. In this case, chloride ingress mainly takes place in the form of diffusion. The diffusion of chloride ions, free and bonded, is generally believed to obey Fick's second law. The unrevised general diffusion equation can be expressed as [29]:

$$
\frac{d C_{f}}{d t}=D_{c l} \cdot \frac{d C_{f}}{d C_{t}} \cdot \operatorname{div}\left[\operatorname{grad}\left(C_{f}\right)\right]
$$

where $\mathrm{C}_{t}$ is the total content of chloride ions per concrete weight $(\%) ; \mathrm{C}_{\mathrm{f}}$ is the content of free chloride ions per concrete weight $(\%) ; \mathrm{t}$ is the diffusing time; $\mathrm{D}_{\mathrm{cl}}$ is the diffusion coefficient; $\mathrm{dC}_{\mathrm{f}} / \mathrm{dC}_{\mathrm{t}}$ is the binding capacity.

Both $\mathrm{C}_{\mathrm{t}}$ and $\mathrm{C}_{\mathrm{f}}$ are functions of the distances from exposed surfaces $x, y, z$ and time $t$.

Several revisions were made to Fick's second law of diffusion based on Equation (1) before developing a comprehensive diffusion model.

\subsection{Time-dependent diffusion coefficient and surface chloride ion content}

The diffusion coefficient of chloride ions varies with time, as the micropores appear and propagate under concrete hydration. Let $D_{\mathrm{cl}}(\mathrm{t})$ be the time-dependent form of the diffusion coefficient at time $t$. Then, the time-dependent diffusion coefficient can be expressed as a decay function [18]:

$D_{\mathrm{cl}}(\mathrm{t})=D_{28} \cdot\left(\frac{t_{28}}{t}\right)^{m}$

where $t_{28}$ is the concrete age of 28 days; $D_{28}$ is the diffusion coefficient at $t_{28} ; m$ is a constant for the decay rate of diffusion coefficient, which depends heavily on the mix proportion of fly ash and slag [18].

In the course of ingress, the content of chloride ions on exposed surfaces also varies with time, adding to the complexity of boundary conditions. The previous studies have proved that the surface chloride ion content increases with time all the way to the saturation point. Here, the timedependent surface chloride ion content is depicted by the power function $[19,20,30]$.

\subsection{Material inhomogeneity and load effect}

In Fick's diffusion model (Equation (1)), concrete is assumed to be a uniform and isotropic material. In reality, however, concrete is not necessarily uniform or isotropic due to the damages induced by the environment, external load and autogenous shrinkage. For better accuracy, $D_{\mathrm{cl}}(\mathrm{t})$ in Equation (1) was replaced with an equivalent diffusion coefficient $D_{\mathrm{e}}(\mathrm{t})$ $[6,7,13]$ :

$$
D_{\mathrm{e}}(\mathrm{t})=K \cdot D_{\mathrm{cl}}(\mathrm{t})
$$

$K=K_{\mathrm{e}} \cdot K_{\mathrm{m}} \cdot K_{\mathrm{y}}$

where $K$ is a comprehensive adjustment coefficient; $K_{\mathrm{e}}$ is the environmental coefficient for environmental degradation; $K_{\mathrm{m}}$ is the material coefficient for concrete elf-deterioration due to alkali-aggregate reaction or autogenous shrinkage; $K_{\mathrm{y}}$ is the load coefficient for external load. $K_{\mathrm{e}}, K_{\mathrm{m}}$ and $K_{\mathrm{y}}$ are subordinate to $K$.

In a flexural member like $\mathrm{RC}$ beam, the microcrack propagation is exacerbated by external load, leading to greater damages and faster chloride diffusion. Considering this phenomenon, the load coefficient $K_{\mathrm{y}}$ was proposed as an amplifying factor for the load effect in a previous study on chloride ingress in concrete under flexural stress [31]. The factor reflects the overall situation, eliminating the need to differentiate between cracked and intact sections. In actual practice, it is rational and convenient to apply this factor. The load coefficient $K_{\mathrm{y}}$ can be expressed as:

$K_{\mathrm{y}}=1+0.51 \cdot\left(\frac{\sigma}{\sigma_{\mathrm{u}}}\right)^{0.6}$

where $\sigma$ is the flexural stress of tensile zone; $\sigma_{\mathrm{u}}$ is the concrete flexural strength.

In this research, the EBFRP-enhanced RC beams are designed to withstand bending load. Hence, the load coefficient was computed by Equation (5), while the values of $K_{\mathrm{e}}$ and $K_{\mathrm{m}}$ were taken from previous research [32-34].

\subsection{Chloride binding capacity}

Some chloride ions entering the concrete are bonded, and do not directly induce rebar corrosion. The chloride binding capacity hinges on the amount of calcium silicate hydrate produced from concrete hydration. The rebar corrosion is mainly attributed to free chloride ions. Hence, the chloride resistance may be underestimated if binding capacity is not included in diffusion analysis [35]. If the content of free 
chloride ions $C_{\mathrm{f}}$ remains at a low level, the binding isotherm will be nearly constant:

binding isotherm $=\frac{d C_{b}}{d C_{f}} \doteq \frac{C_{b}}{C_{f}}=R$

where $C_{\mathrm{b}}$ is the content of bonded chloride ions per concrete weight $(\%) ; R$ is a constant.

The content of bonded chloride ions and that of free chloride ions add up to the total content of chloride ions per concrete weight $\mathrm{C}_{\mathrm{t}}$ :

$C_{\mathrm{t}}=C_{b}+C_{f}$

\subsection{Enhancement behaviour}

In the EBFRP-enhanced RC beams, the ERP sheets at the beam bottom are bonded by epoxy resin. With excellent sealing performance [36], epoxy resin has been widely adopted in engineering projects to protect rebars from corrosion. Many scholars have sealed up non-diffusional surfaces of concrete specimens [37-39] with epoxy coating, thus achieving 1D diffusion. Previous research has shown that epoxy coating can significantly reduce the chloride diffusion rate in both saturated and non-saturated conditions. Therefore, the enhancement behaviour in our research is considered as the closure of diffusion pathways at the bottom of the beams. It requires a proper change of boundary conditions in diffusion analysis.

\subsection{Revised diffusion equation}

Considering the above factors like time-dependent diffusion coefficient, time-dependent surface chloride ion content, material inhomogeneity, load effect, binding capacity and bonding behaviour, a revised diffusion equation was established by substituting Equations (2) (7) into Equation (1):

$$
\frac{d C_{f}}{d t}=\frac{K_{\mathrm{e}} \cdot K_{\mathrm{m}} \cdot K_{\mathrm{y}} \cdot D_{28} \cdot t_{28}{ }^{m}}{1+R} \cdot t^{-m} \cdot \operatorname{div}\left[\operatorname{grad}\left(C_{f}\right)\right]
$$

The term containing time $t$ on the right side increases the complexity in the solution to Equation (8). For simplicity, the second term on the right side was moved to the left side, and two new parameters $T$ and $D_{\text {ee }}$ were introduced below:

$$
\begin{aligned}
& \frac{d C_{f}}{t^{-m} \cdot d t}=\frac{K_{\mathrm{e}} \cdot K_{\mathrm{m}} \cdot K_{\mathrm{y}} \cdot D_{28} \cdot t_{28}{ }^{m}}{1+R} \cdot \operatorname{div}\left[\operatorname{grad}\left(C_{f}\right)\right] \\
& d T=\int_{0}^{t} t^{-m} \cdot d t \quad \Rightarrow \quad T=\int_{0}^{t} t^{-m} \cdot d t=\frac{1}{1-m} \cdot t^{1-m} \\
& D_{e e}=\frac{K_{\mathrm{e}} \cdot K_{\mathrm{m}} \cdot K_{\mathrm{y}} \cdot D_{28} \cdot t_{28}{ }^{m}}{1+R}
\end{aligned}
$$

where $T$ and $D_{\text {ee }}$ are nominal diffusion time and nominal diffusion coefficient, respectively.

Substituting Equations (10) and (11) into Equation (8) or (9), the revised diffusion equation can be rewritten as: $\frac{d C_{f}}{d T}=D_{e e} \cdot \operatorname{div}\left[\operatorname{grad}\left(C_{f}\right)\right]$

Now, the revised diffusion equation has the same form as the general diffusion model (Equation (1)). Note that the nominal diffusion coefficient $D_{\mathrm{ee}}$ in the revised diffusion equation remains constant under given material properties. This coefficient both reflect the time-dependence and facilitate the solution to the revised diffusion model.

The diffusion boundary conditions in Equation (12) can be directly applied to the chloride ingress analysis on unenhanced beam. For enhanced beam, however, the diffusion boundary conditions should be changed according to the bonding behaviour in Section 2.5. Thus, the revised boundary model is applicable to chloride diffusion analysis in both enhanced and unenhanced $\mathrm{RC}$ beams.

\section{MODEL ESTABLISHMENT}

This section aims to build a full-scale model for chloride ingress in EBFRP-enhanced RC beams considering both longitudinal rebars and stirrups. For each beam, the sectional size is $200 \mathrm{~mm}$ by $500 \mathrm{~mm}$. Three parallel $12 \mathrm{~mm}$-diameter rebars were arranged at equal intervals on the top of the beam, and six parallel $16 \mathrm{~mm}$-diameter rebars were arranged in two rows at equal intervals on the bottom of the beam. The arrangement of stirrups is described in later section. Chloride diffusion is blocked at the positions of the rebars. Similar to previous studies, the rebars were modelled as a cavity or a hole in concrete member with zero diffusion coefficient [6, 9-10].

The top of the beam is sealed, because the beam and the top slab were casted as a whole in actual operation. The chloride ion content at points $1 \sim 4$ on the front faces of rebars are the focus of our discussion. For simplicity, a $250 \mathrm{~mm}$ long beam segment was extracted for further analysis (Figure 1). The simplification does not affect the robustness of the research because there is no gradient of surface chloride ion content along the $\mathrm{RC}$ beam. Before enhancement, the beam has three exposed boundaries prone to chloride ingress: the left side, the right side and the bottom. After EBFRP enhancement, only two exposed boundaries remain: the left side and the right side. Here, both pre- and post-enhancement chloride diffusions are under discussion.

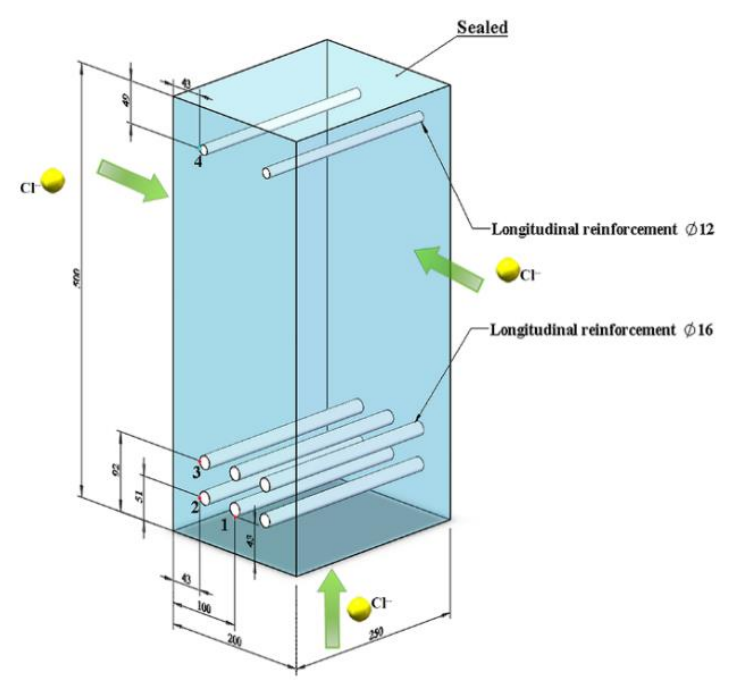

(a) Pre-enhancement chloride ingress 


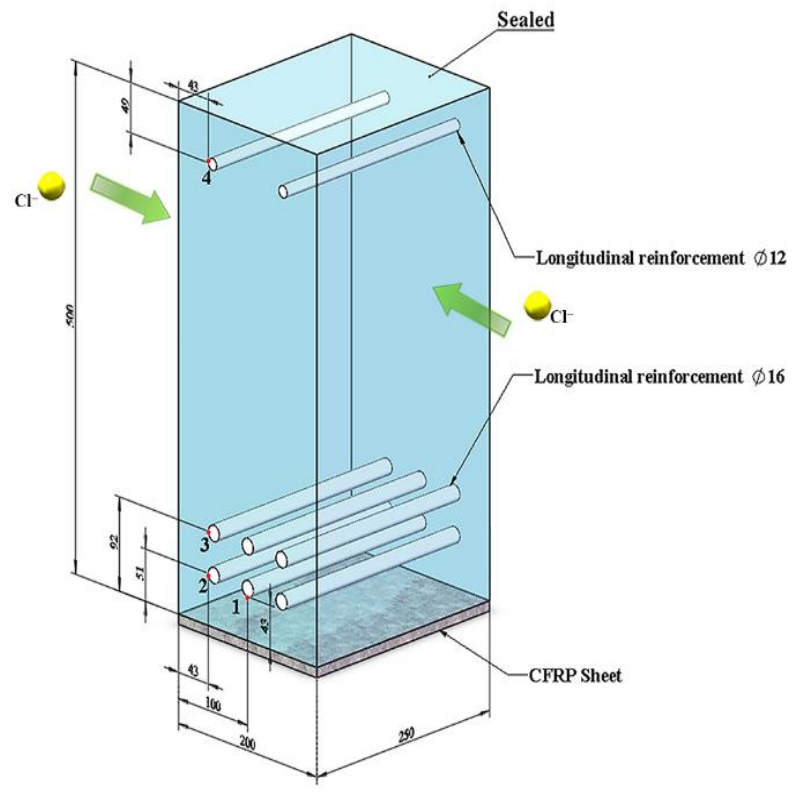

(b) Post-enhancement chloride ingress

Figure 1. Beam geometry and chloride ingress pathways

To realize accurate simulation of chloride diffusion in marine environment, the simulation parameters were taken from the field test by Thomas [18]: the diffusion coefficient at the concrete age of 28 days is $6 \times 10^{-12} \mathrm{~m}^{2} / \mathrm{s}$; the decay rate for diffusion coefficient $m$ is 0.7 . The time-dependent surface chloride ion content $C_{\mathrm{s}}(\mathrm{t})$ was obtained as below, with the unit of time $t$ being year (Figure 2).

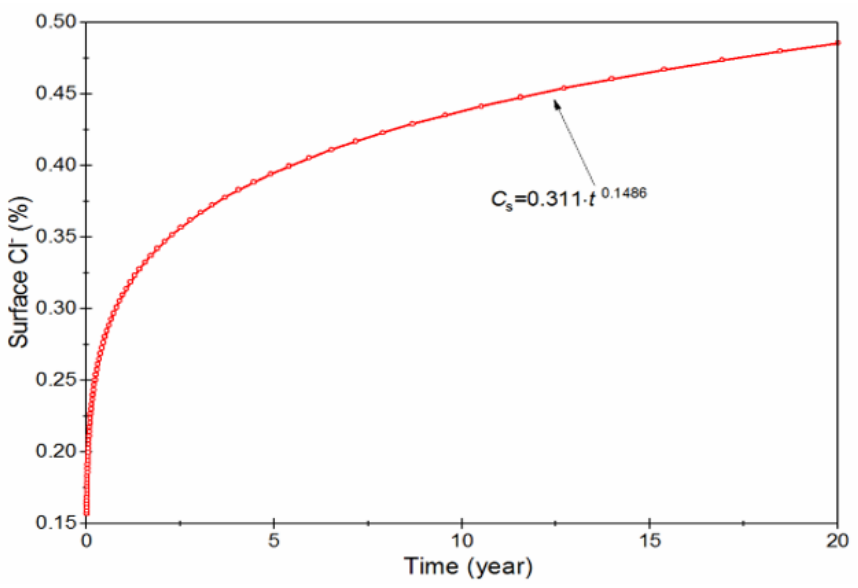

Figure 2. The time-dependent surface chloride ion content

The load coefficient Ky was calculated according to Equation (5) to illustrate the effect of bending load. The value of $\sigma / \sigma_{u}$ was set to 0.6 before the enhancement. During the enhancement, each beam was unloaded for crack repair, and the FRP sheets were bonded by epoxy resin. Then, the enhancement beam was applied with the original bending load.

After the enhancement, the beam stress was partly relieved due to the increase in member stiffness. Meanwhile, there was a decline in member deformation, resulting in the closure of microcracks and slowdown of diffusion rate. Thus, the value of $\sigma / \sigma_{\mathrm{u}}$ was set to a lower level (0.3) after the enhancement, leading to a smaller $K_{\mathrm{y}}$.

Overall, the value of load coefficient $K_{\mathrm{y}}$ was set to 1.375 and 1.248 before and after enhancement, respectively. The values of the binding isotherm $R$, environmental coefficient $K_{\mathrm{e}}$, and material coefficient $K_{\mathrm{m}}$ were set to 2.14, 0.72 and 2 in light of References [32, 40].

Based on the above parameters, the revised diffusion model (Equation (12)) was numerically solved by finite-element analysis (FEA) on Abaqus, with the aim to reveal the effect of enhancement on chloride diffusion, the effect of longitudinal bars and stirrups on chloride diffusion, and the results and efficiencies of 2D and 3D models. During model solution, 2D diffusion analysis was carried out first, followed by 3D diffusion analysis, which is closest to the real situation but seldom used in previous studies. The grids were densified along the diffusion boundaries, where the chloride ion content gradient is the steepest. The meshing of $2 \mathrm{D}$ and $3 \mathrm{D}$ models is shown in Figure 3.

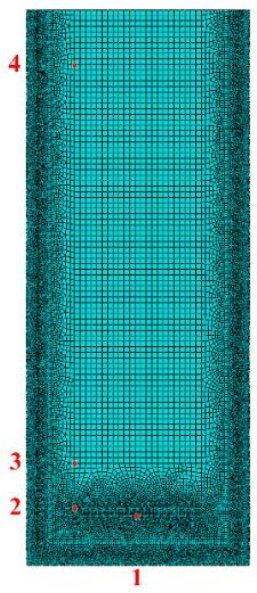

(a) 2D model without rebars

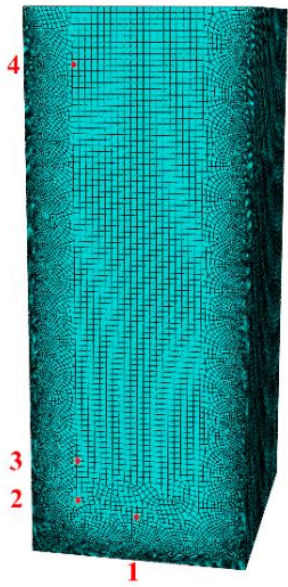

(c) 3D model without rebars

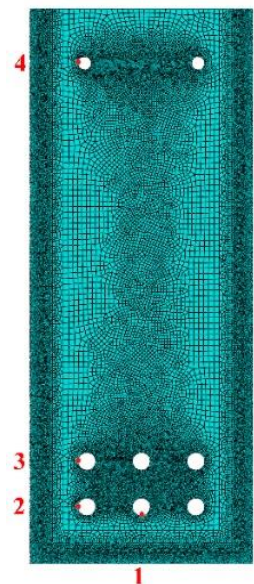

(b) 2D model with rebars

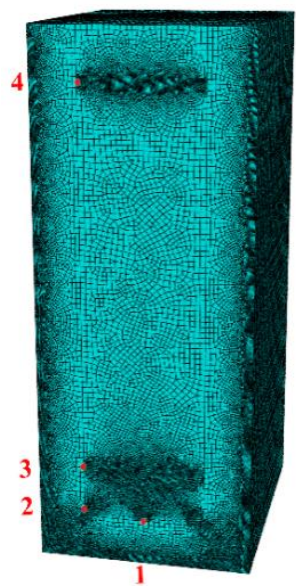

(d) 3D model with rebars
Figure 3. Finite-element meshing of $2 \mathrm{D}$ and 3D models

\section{RESULTS AND DISCUSSION}

\subsection{Effect of enhancement on chloride diffusion}

The boundary conditions were changed properly based on the enhancement behaviour. Here, the chloride diffusion was calculated for different beams: unenhanced, enhanced in the $5^{\text {th }}$ year, enhanced in the $10^{\text {th }}$ year and enhanced in the $15^{\text {th }}$ year. Figure 4 records the chloride ion contents at points 1 4 (Figure 3 ) for RC beam models with or without rebars. The effect of stirrups is not considered here. 

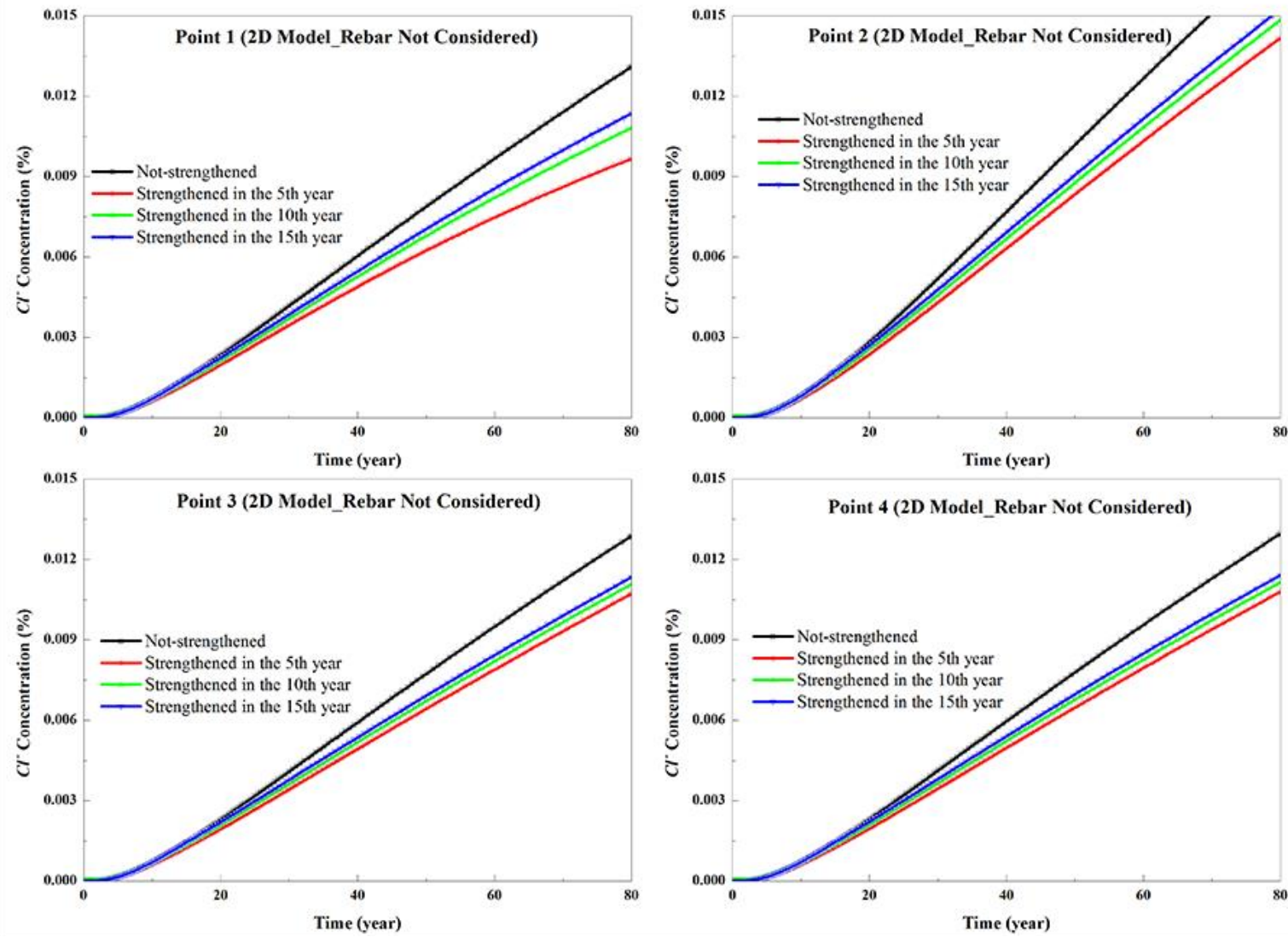

(a) Without rebars
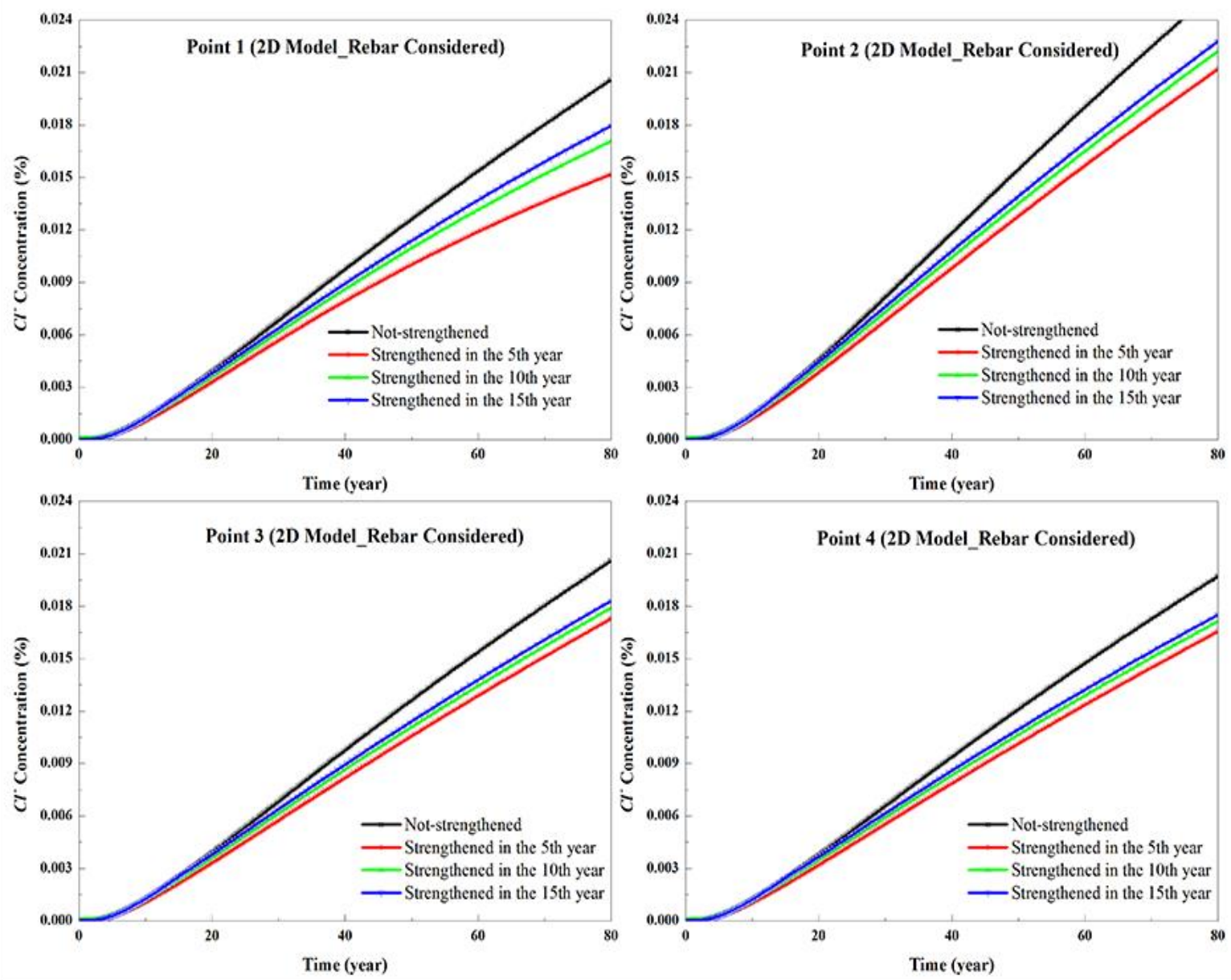

(b) With rebars

Figure 4. Temporal variation in chloride ion content of unenhanced and enhanced beams 
Compared to the chloride ion content-time curve (hereinafter referred to as the content-time curve) of unenhanced beam, the content-time curves of different enhanced beams are closer to the time axis (t-axis) in different degrees. For all target points (1 5), the content-time curve of the beam enhanced in the $5^{\text {th }}$ year had the most obvious bias towards the time-axis, followed by that of the beam enhanced in the $10^{\text {th }}$ year and that of the beam enhanced in the $15^{\text {th }}$ year. The results show that the EBFRP enhancement can reduce the chloride ion content in concrete, thus extending the initial time of rebar corrosion. Besides, the earlier the enhancement, the fewer the chloride ions on the front faces of rebars. Thus, early enhancement helps to enhance chloride resistance and prolong service life.

These findings are verified by the comparison of chloride ion contents before and after enhancement in Table 1. As shown in Table 1 , the beam enhanced in the $5^{\text {th }}$ year (the earliest one) enjoyed the greatest reduction in chloride ion content, followed by the beam enhanced in the $10^{\text {th }}$ year and that enhanced in the $15^{\text {th }}$ year, and the reduction increases with the diffusion time.

Table 1. Comparison of chloride ion contents per concrete weight (\%) before and after enhancement

\begin{tabular}{|c|c|c|c|c|c|c|c|c|c|}
\hline & Variables & 20 year & $\Delta C_{\mathrm{f}}, \%$ & 40 year & $\Delta C_{\mathrm{f}}, \%$ & 60 year & $\Delta C_{\mathrm{f}, \%} \%$ & 80 year & $\Delta C_{\mathrm{f},}, \%$ \\
\hline \multirow{4}{*}{ Point 1} & Not strengthened & 0.00393 & - & 0.00981 & - & 0.01537 & - & 0.02059 & - \\
\hline & Strengthened in the 5 th year & 0.00336 & -14.6 & 0.00798 & -18.7 & 0.01190 & -22.6 & 0.01518 & -26.3 \\
\hline & Strengthened in the 10 th year & 0.00363 & -7.2 & 0.00857 & -12.7 & 0.01317 & -14.3 & 0.01708 & -17.0 \\
\hline & Strengthened in the 15 th year & 0.00389 & -1.2 & 0.00900 & -8.3 & 0.01364 & -11.3 & 0.01795 & -12.8 \\
\hline \multirow{4}{*}{ Point 2} & Not strengthened & 0.00460 & - & 0.01189 & - & 0.01901 & - & 0.02583 & - \\
\hline & Strengthened in the 5 th year & 0.00391 & -14.9 & 0.00988 & -16.9 & 0.01568 & -17.5 & 0.02119 & -17.9 \\
\hline & Strengthened in the 10 th year & 0.00424 & -7.7 & 0.01037 & -12.8 & 0.01652 & -13.1 & 0.02221 & -14.0 \\
\hline & Strengthened in the 15 th year & 0.00455 & -1.1 & 0.01088 & -8.5 & 0.01688 & -11.2 & 0.02279 & -11.8 \\
\hline \multirow{4}{*}{ Point 3} & Not strengthened & 0.00394 & - & 0.00982 & - & 0.01538 & - & 0.02060 & - \\
\hline & Strengthened in the 5 th year & 0.00337 & -14.4 & 0.00824 & -16.1 & 0.01238 & -16.2 & 0.01729 & -16.1 \\
\hline & Strengthened in the 10 th year & 0.00364 & -7.6 & 0.00861 & -12.3 & 0.01346 & -12.5 & 0.01790 & -13.1 \\
\hline & Strengthened in the 15 th year & 0.00389 & -1.2 & 0.00901 & -8.2 & 0.01372 & -10.8 & 0.01830 & -11.2 \\
\hline \multirow{4}{*}{ Point 4} & Not strengthened & 0.00380 & - & 0.00943 & - & 0.01473 & - & 0.01970 & - \\
\hline & Strengthened in the 5 th year & 0.00325 & -14.3 & 0.00792 & -16.0 & 0.01235 & -16.2 & 0.01655 & -16.0 \\
\hline & Strengthened in the 10 th year & 0.00351 & -7.5 & 0.00827 & -12.3 & 0.01290 & -12.4 & 0.01714 & -13.0 \\
\hline & Strengthened in the 15 th year & 0.00375 & -1.2 & 0.00866 & -8.2 & 0.01315 & -10.7 & 0.01751 & -11.1 \\
\hline
\end{tabular}

Note: $\Delta \mathrm{C}_{\mathrm{f}}$ is the change of $\mathrm{Cl}^{-}$relative to the chloride ion content of the unenhanced case.
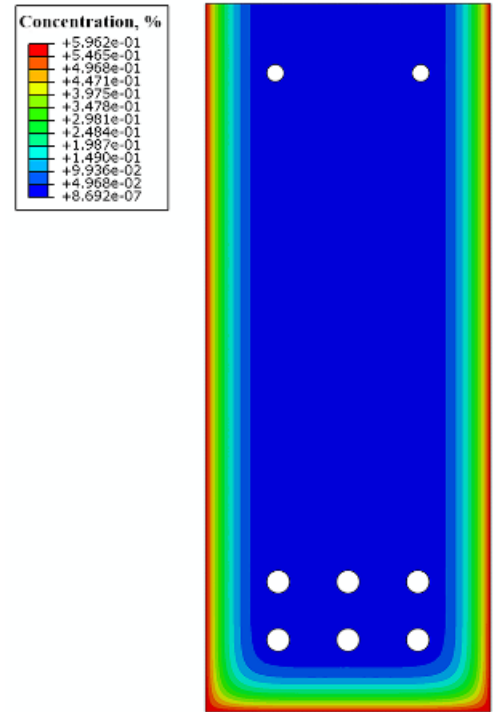

(a) Pre-enhancement

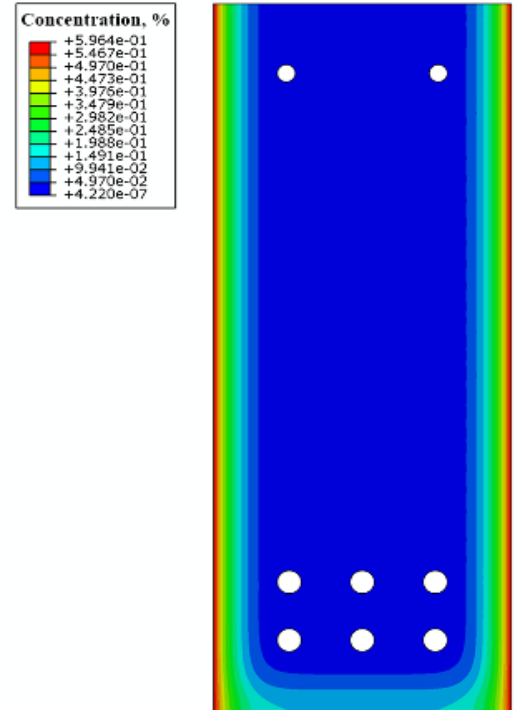

(b) Post-enhancement

Figure 5. Contour plot of FEA results

Figure 5 is the contour plot of the FEA results. It is clear that chloride ion dilution occurred near the bottom, where the FRP sheets were bonded. This is because the enhancement blocks the diffusion pathways at the bottom. The finding further verifies the bonding effect.

\subsection{Effect of rebars and stirrups}

The chloride ion contents at points 1,2 and 4 were selected to study the effect of longitudinal bars on diffusion (Figure 6) without considering stirrups. The beam models with or without rebars were respectively unenhanced, enhanced in the $5^{\text {th }}$ year, enhanced in the $10^{\text {th }}$ year and enhanced in the $15^{\text {th }}$ year. Clear differences were observed in chloride ion content among the beams, which agree well with the results in References [6,910]. The chloride ion contents with or without rebars were compared and recorded in Table 2.

For all beams, the content-time curves exhibit an obvious rising trend under the effect of rebars, and the chloride ion content increased by $50 \% \sim 90 \%$. The trends echo with the 
finding in Reference [9]: the chloride ion content increases in the range of $30 \% \sim 90 \%$. This means the longitudinal bars in concrete can obstruct the diffusion pathways of chloride ions and attract more chloride ions near the rebars. Therefore, the chloride ion content will be underestimated for EBFRPenhanced $\mathrm{RC}$ members if the longitudinal bars are not considered.
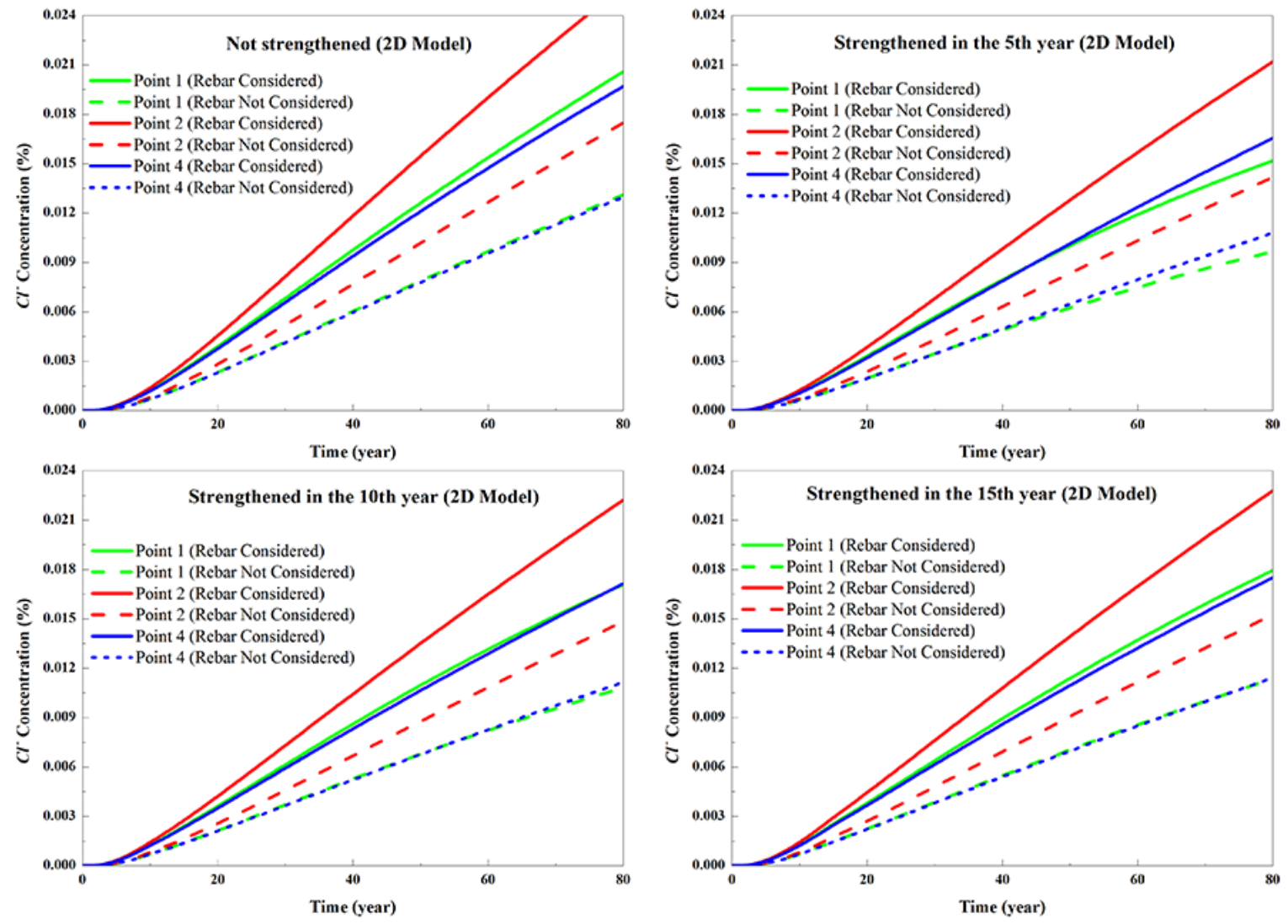

Figure 6. Temporal variation in chloride ion content of unenhanced and enhanced beams considering longitudinal bars

Table 2. Comparison of chloride ion contents per concrete weight (\%) between beams with or without rebars

\begin{tabular}{|c|c|c|c|c|c|c|c|c|c|c|}
\hline & Variables & & 20 year & $\begin{array}{c}\Delta \mathrm{C}_{\mathrm{f}} \\
\%\end{array}$ & 40 year & $\begin{array}{c}\Delta \mathrm{C}_{\mathrm{f}} \\
\%\end{array}$ & 60 year & $\begin{array}{c}\Delta \mathrm{C}_{\mathrm{f}} \\
\%\end{array}$ & 80 year & $\begin{array}{l}\Delta C_{\mathrm{f}} \\
\%\end{array}$ \\
\hline \multirow{4}{*}{ Point 1} & Not strengthened & $\begin{array}{c}\text { No bar } \\
\text { With bar }\end{array}$ & $\begin{array}{l}0.0026 \\
0.0043\end{array}$ & +68.06 & $\begin{array}{l}0.0045 \\
0.0107\end{array}$ & +63.44 & $\begin{array}{l}0.0099 \\
0.0159\end{array}$ & +61.04 & $\begin{array}{l}0.0134 \\
0.0213\end{array}$ & +59.10 \\
\hline & Strengthened in the 5 th year & $\begin{array}{c}\text { No bar } \\
\text { With bar }\end{array}$ & $\begin{array}{l}0.0023 \\
0.0039\end{array}$ & +68.33 & $\begin{array}{l}0.0050 \\
0.0083\end{array}$ & +64.15 & $\begin{array}{l}0.0076 \\
0.0122\end{array}$ & +61.15 & $\begin{array}{l}0.0098 \\
0.0155\end{array}$ & +58.85 \\
\hline & Strengthened in the 10th year & $\begin{array}{l}\text { No bar } \\
\text { With bar }\end{array}$ & $\begin{array}{l}0.0024 \\
0.0041\end{array}$ & +68.28 & $\begin{array}{l}0.0058 \\
0.0095\end{array}$ & +63.94 & $\begin{array}{l}0.0082 \\
0.0133\end{array}$ & +61.65 & $\begin{array}{l}0.0110 \\
0.0175\end{array}$ & +59.35 \\
\hline & Strengthened in the 15 th year & $\begin{array}{c}\text { No bar } \\
\text { With bar }\end{array}$ & $\begin{array}{l}0.0025 \\
0.0042\end{array}$ & +68.14 & $\begin{array}{l}0.0059 \\
0.0097\end{array}$ & +63.90 & $\begin{array}{l}0.0091 \\
0.0146\end{array}$ & +61.32 & $\begin{array}{l}0.0116 \\
0.0185\end{array}$ & +59.54 \\
\hline \multirow{4}{*}{ Point 2} & Not strengthened & $\begin{array}{c}\text { No bar } \\
\text { With bar }\end{array}$ & $\begin{array}{l}0.0030 \\
0.0050\end{array}$ & +65.75 & $\begin{array}{l}0.0081 \\
0.0128\end{array}$ & +57.92 & $\begin{array}{l}0.0126 \\
0.0195\end{array}$ & +54.08 & $\begin{array}{l}0.0176 \\
0.0265\end{array}$ & +51.11 \\
\hline & Strengthened in the 5 th year & $\begin{array}{l}\text { No bar } \\
\text { With bar }\end{array}$ & $\begin{array}{l}0.0027 \\
0.0046\end{array}$ & +66.38 & $\begin{array}{l}0.0064 \\
0.0103\end{array}$ & +60.10 & $\begin{array}{l}0.0104 \\
0.0162\end{array}$ & +56.31 & $\begin{array}{l}0.0142 \\
0.0219\end{array}$ & +53.77 \\
\hline & Strengthened in the 10th year & $\begin{array}{c}\text { No bar } \\
\text { With bar }\end{array}$ & $\begin{array}{l}0.0028 \\
0.0047\end{array}$ & +66.13 & $\begin{array}{l}0.0072 \\
0.0114\end{array}$ & +58.99 & $\begin{array}{l}0.0106 \\
0.0166\end{array}$ & +55.72 & $\begin{array}{l}0.0149 \\
0.0228\end{array}$ & +52.84 \\
\hline & Strengthened in the 15 th year & $\begin{array}{c}\text { No bar } \\
\text { With bar }\end{array}$ & $\begin{array}{l}0.0029 \\
0.0049\end{array}$ & +65.88 & $\begin{array}{l}0.0074 \\
0.0117\end{array}$ & +58.74 & $\begin{array}{l}0.0117 \\
0.0181\end{array}$ & +54.82 & $\begin{array}{l}0.0154 \\
0.0234\end{array}$ & +52.44 \\
\hline \multirow{4}{*}{ Point 4} & Not strengthened & $\begin{array}{c}\text { No bar } \\
\text { With bar }\end{array}$ & $\begin{array}{l}0.0025 \\
0.0041\end{array}$ & +61.75 & $\begin{array}{l}0.0065 \\
0.0101\end{array}$ & +56.63 & $\begin{array}{l}0.0098 \\
0.0151\end{array}$ & +54.01 & $\begin{array}{l}0.0133 \\
0.0202\end{array}$ & +51.90 \\
\hline & Strengthened in the 5 th year & $\begin{array}{l}\text { No bar } \\
\text { With bar }\end{array}$ & $\begin{array}{l}0.0023 \\
0.0038\end{array}$ & +62.14 & $\begin{array}{l}0.0052 \\
0.0082\end{array}$ & +57.92 & $\begin{array}{l}0.0082 \\
0.0128\end{array}$ & +55.17 & $\begin{array}{l}0.0112 \\
0.0171\end{array}$ & +53.18 \\
\hline & Strengthened in the 10th year & $\begin{array}{l}\text { No bar } \\
\text { With bar }\end{array}$ & $\begin{array}{l}0.0024 \\
0.0039\end{array}$ & +62.00 & $\begin{array}{l}0.0058 \\
0.0091\end{array}$ & +57.32 & $\begin{array}{l}0.0083 \\
0.0129\end{array}$ & +55.05 & $\begin{array}{l}0.0115 \\
0.0176\end{array}$ & +52.93 \\
\hline & Strengthened in the 15 th year & $\begin{array}{l}\text { No bar } \\
\text { With bar }\end{array}$ & $\begin{array}{l}0.0025 \\
0.0040\end{array}$ & +61.83 & $\begin{array}{l}0.0059 \\
0.0093\end{array}$ & +57.18 & $\begin{array}{l}0.0091 \\
0.0140\end{array}$ & +54.49 & $\begin{array}{l}0.0118 \\
0.0180\end{array}$ & +52.77 \\
\hline
\end{tabular}

Note: $\Delta \mathrm{C}_{\mathrm{f}}$ is the change of $\mathrm{Cl}^{-}$relative to the chloride ion content of the unenhanced case. 
Next, several 8mm-diameter stirrups were added to the existing longitudinal bars at an equal interval of $100 \mathrm{~mm}$ to explore their effect on chloride diffusion. Similar to the results of longitudinal bars, diffusion cannot occur within the stirrups. Thus, the stirrups were also modelled as cavities in RC beam.
Figure 7 illustrates the geometry of enhanced beam considering both longitudinal bars and stirrups. The addition of stirrups complicates the geometry of the model, adding to the difficulty in meshing.
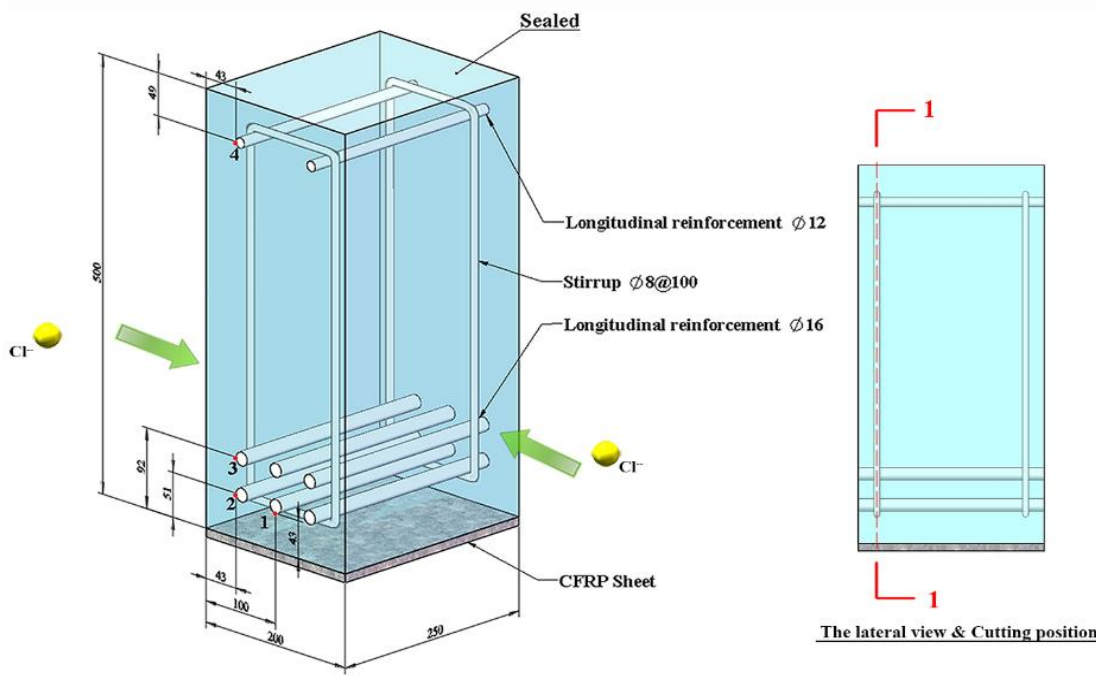

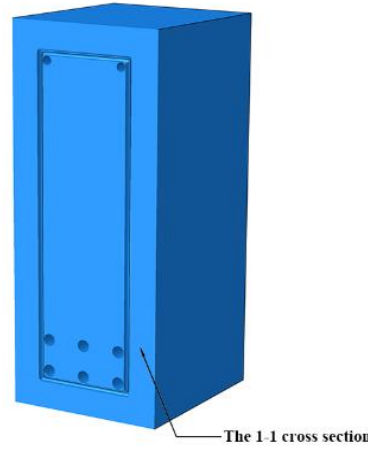

The cut view of beam mode

Figure 7. Geometry of enhanced beam considering both longitudinal bars and stirrups
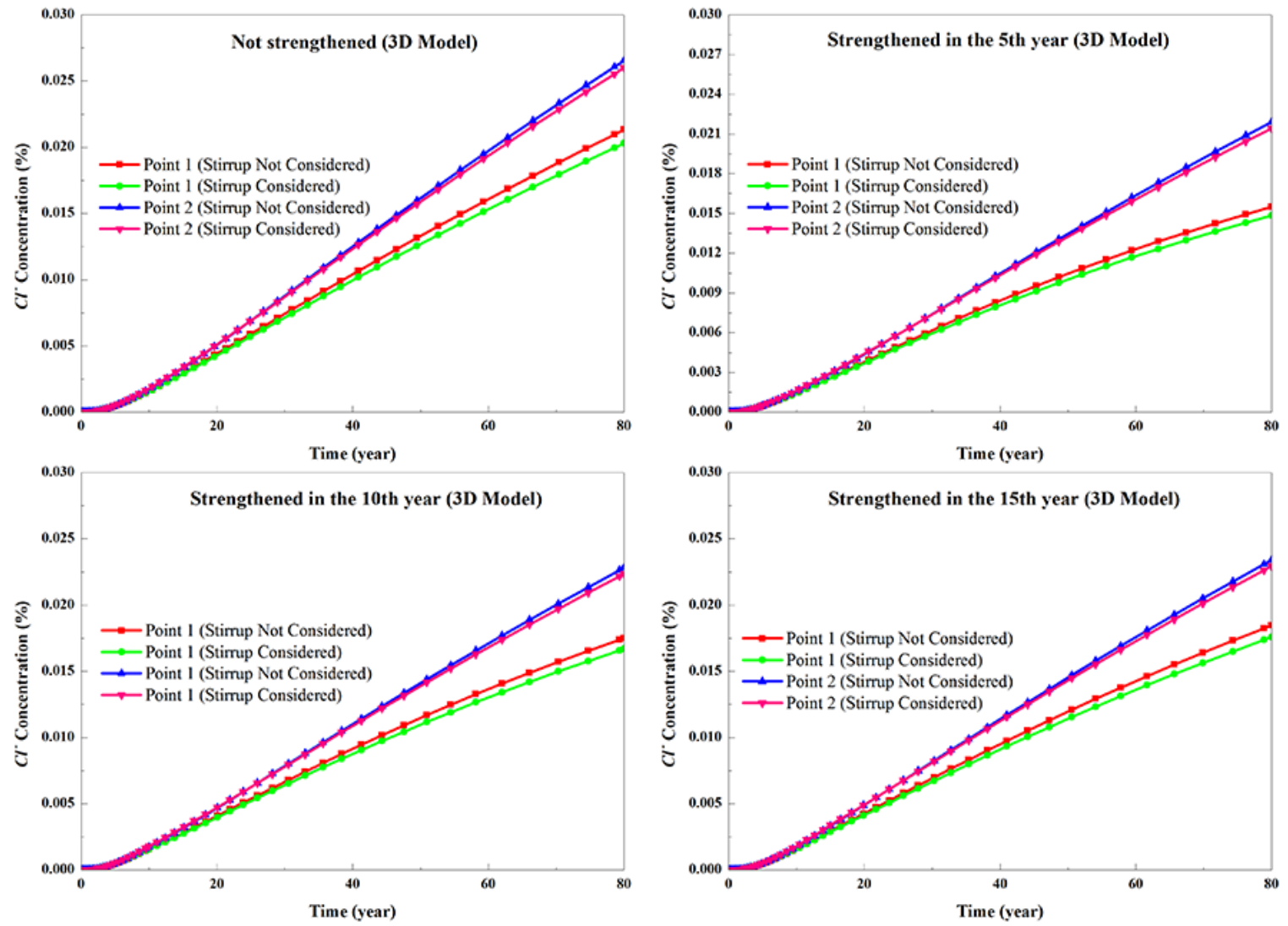

Figure 8. Change of $\mathrm{Cl}^{-}$versus time, both longitudinal bars and stirrups considered

Figure 8 presents the chloride ion contents at points 1 and 2 in the beam models with or without stirrups. These beam models were respectively unenhanced, enhanced in the $5^{\text {th }}$ year, enhanced in the $10^{\text {th }}$ year and enhanced in the $15^{\text {th }}$ year. In each model, the chloride ion content was smaller than that before the addition of stirrups; the chloride ion content stayed on similar levels across the models. The same features were observed at points 3 and 4 . The results indicate that stirrups have no major impact on chloride ion content if the effect of longitudinal bars has been considered.

The possible reasons are as follows. First, points 1 4 may not be the ideal positions to evaluate the effect of stirrups, because none of them is located on the front faces of stirrups. Second, the stirrups, smaller than the longitudinal bars in diameter, may fail to block the chloride diffusion pathways entirely. 
Whichever the reason, the presence of stirrups can be neglected in the analysis of chloride ion content at the apex of longitudinal bars, as long as the effect of longitudinal bars has been considered. This finding may help to simplify the model and reduce the computing cost.

\subsection{Comparison between $2 \mathrm{D}$ and $3 \mathrm{D}$ models}

Unlike most of the previous studies, this paper establishes both 2D and 3D diffusion models, and compares their
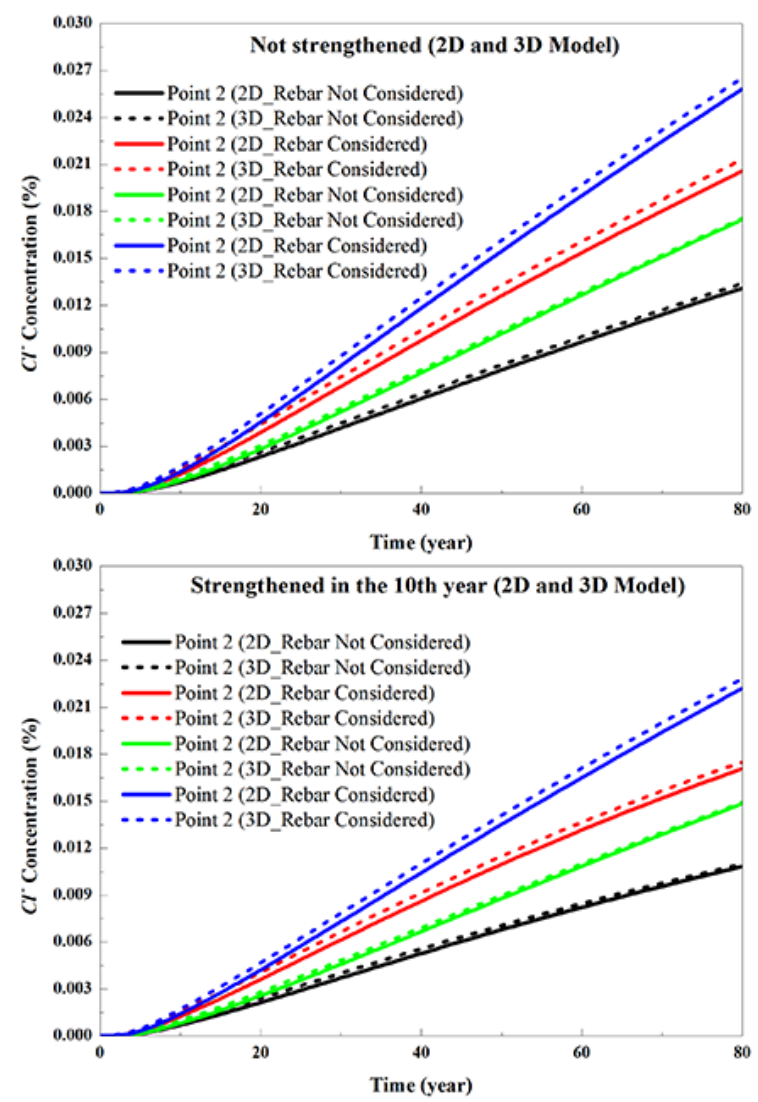

calculation results and run time. According to the calculation results of 2D and 3D models (Figure 9), 2D models outputted slightly smaller results than 3D models, in all cases (i.e. unenhanced beam, beam enhanced in the $5^{\text {th }}$ year, beam enhanced in the $10^{\text {th }}$ year, and beam enhanced in the $15^{\text {th }}$ year). A possible explanation lies in the lack of gradient of surface chloride ion content. Therefore, 3D diffusion can be simplified as $2 \mathrm{D}$ diffusion in the cross section.
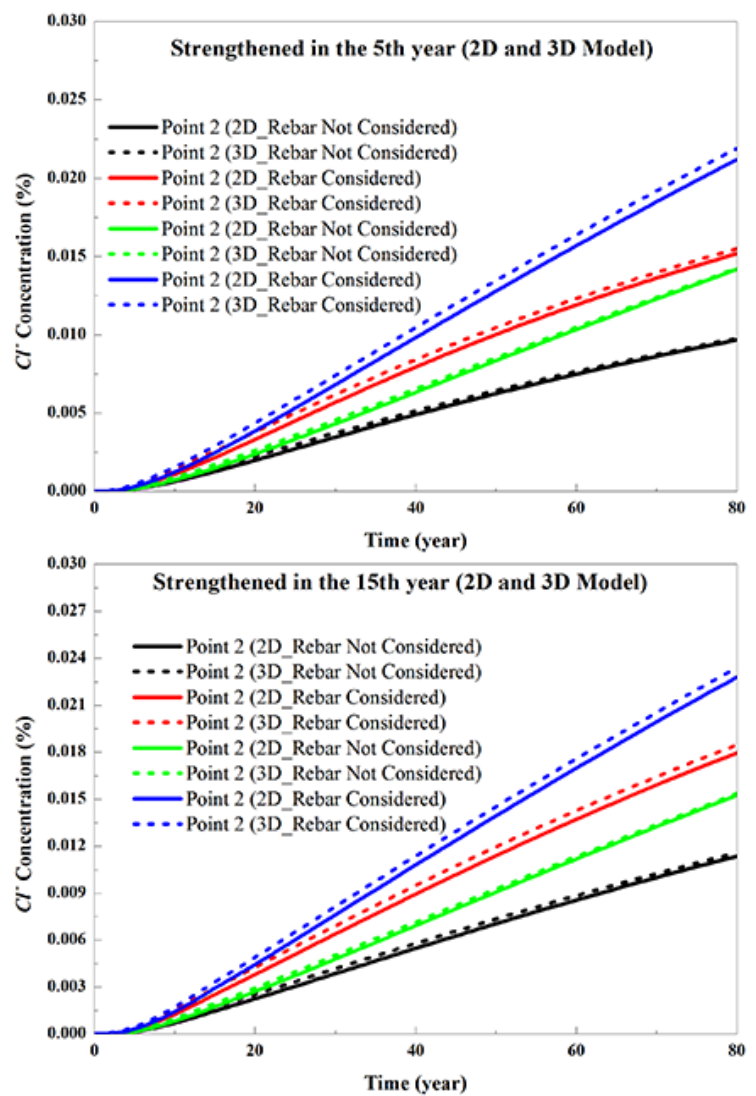

Figure 9. Comparison of calculation results between $2 \mathrm{D}$ and 3D models

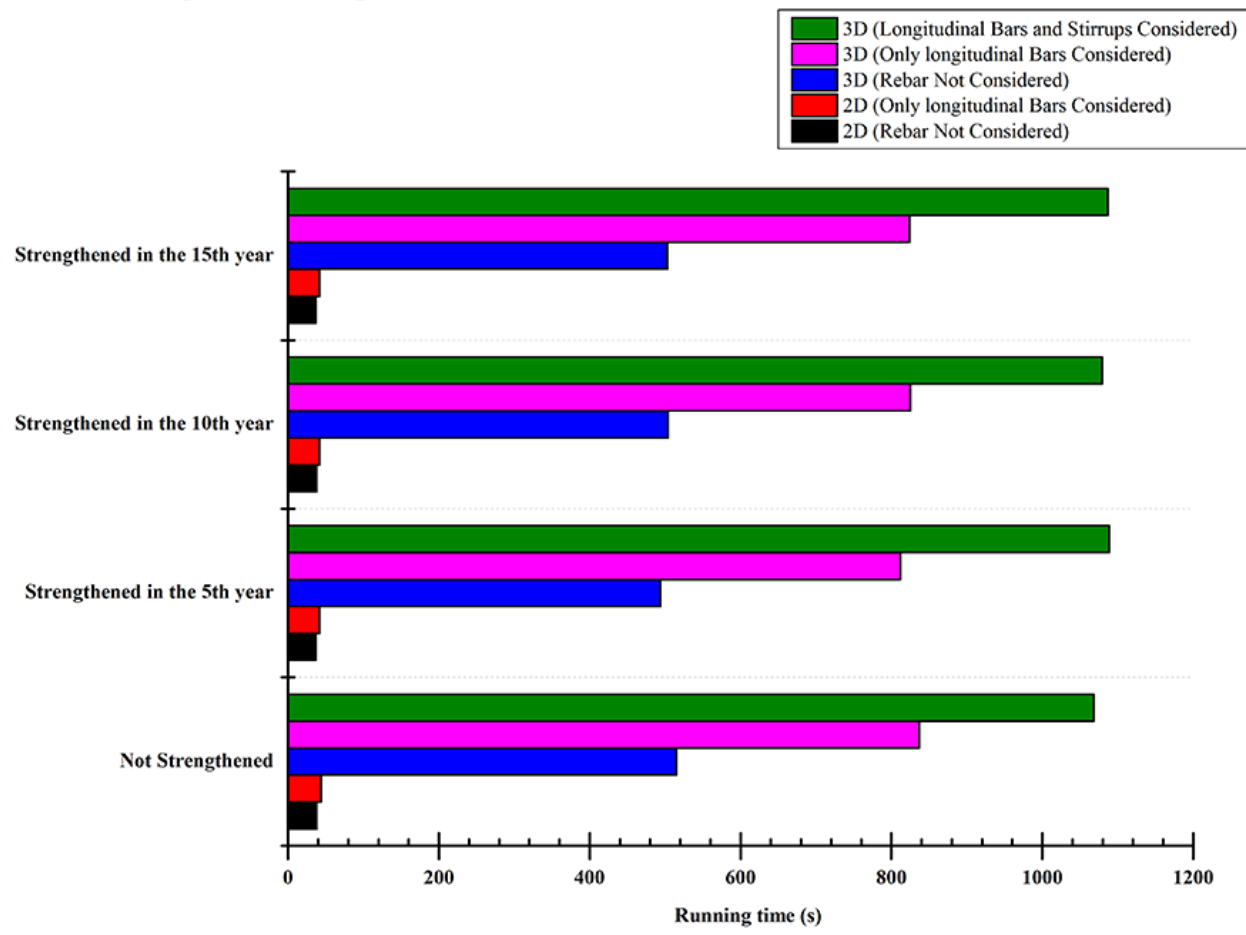

Figure 10. Run time of $2 \mathrm{D}$ and $3 \mathrm{D}$ models 
Figure 10 displays the run time of $2 \mathrm{D}$ and $3 \mathrm{D}$ models. It is clear that $3 \mathrm{D}$ models required a much longer run time than $2 \mathrm{D}$ models, despite the sparser grid density of 3D models. The long run time of 3D models may be attributed to two factors. First, a 3D model has much more grids than a 2D model, because of the additional dimension. Second, based on the theories on finite-element method, 3D diffusion analysis runs on a higher-dimensional calculation matrix than that of $2 \mathrm{D}$ diffusion analysis.

Furthermore, the 2D models for enhanced beam had a similar run time with the 2D models for unenhanced beam. By contrast, the run time surged up with the increase of model complexity. The longest run time belongs to the case considering both longitudinal bars and stirrups. The second longest run time occurred in the case considering longitudinal bars only. The run time was minimum when both longitudinal bars and stirrups were neglected. Thus, the run time of 3D models mainly depends on the modelling complexity. To sum up, 2D model is easier and less costly to simulate chloride ingress in concrete structures.

Through the above analysis, 2D model is more recommended for chloride diffusion analysis than $3 \mathrm{D}$ model, if there is no gradient of surface chloride ion content along the longitudinal direction.

\section{CONCLUSIONS}

Based on Fick's second law of diffusion, this paper develops a revised diffusion model for chloride ingress in EBFRP-enhanced RC beam. The revision process incorporates many findings in existing studies, including timedependent diffusion coefficient, time-dependent surface chloride ion content, chloride binding effect, material inhomogeneity and load effect. Then, the boundary conditions were properly changed to fit the enhancement behaviour. Later, the revised diffusion model was numerically solved by the FEA on Abaqus, aiming to reveal the effect of enhancement on chloride diffusion, the effect of longitudinal bars and stirrups on chloride diffusion, and the results and efficiencies of $2 \mathrm{D}$ and $3 \mathrm{D}$ models. Through the analysis of simulation results, the main conclusions were drawn as follows.

In our research, the ERP sheets at the beam bottom are bonded by epoxy resin. With excellent sealing performance. The enhancement can effectively block the diffusion pathways at the bottom of the beams, leading to changes of the boundary conditions. If the beam is unenhanced, there is no need to alter the boundary conditions. Therefore, the EBFRP enhancement applies to both unenhanced and enhanced beams.

The EBFRP enhancement can reduce the chloride ion content on the front faces of rebars, and chloride ion dilution occurred near the bonding area of FRP sheets, whether there are rebars or not. The earlier the enhancement, the fewer the chloride ions on the front faces of rebars. Thus, the enhancement helps to extend the initial time of rebar corrosion and prolong service life of the concrete.

For both enhanced and unenhanced RC beams, the longitudinal bars lead to pronounced increase of chloride ion content at the apex of rebars, which agrees well with the results in previous research. The increment can be as high as $50 \% \sim 90 \%$. To avoid overestimation of service life of enhanced RC beam, it is necessary to consider the effect of rebars in the prediction of chloride ion content. Besides, the presence of stirrups can be neglected in the analysis of chloride ion content at the apex of longitudinal bars, as long as the effect of longitudinal bars has been considered.

The calculation results of 2D models are only slightly smaller than those of 3D models, indicating that 3D diffusion can be reasonably simplified as 2D diffusion if there is no gradient of surface chloride ion content in the longitudinal direction. Nevertheless, 3D models need a much longer run time than 2D models, owing to their high number of grids and modelling complexity. Therefore, 2D model is more recommended for chloride diffusion analysis than 3D model, if there is no gradient of surface chloride ion content along the longitudinal direction.

\section{ACKNOWLEDGMENTS}

The authors are grateful to the finical support from the Key Projects of College Outstanding Achievements Transformation (KJZH14220).

\section{REFERENCES}

[1] Chen W, Pham TM, Sichembe H. (2018). Experimental study of flexural behaviour of RC beams strengthened by longitudinal and U-shaped basalt FRP sheet. Composites Part B Engineering 134: 114-126. https://doi.org/10.1016/j.compositesb.2017.09.053

[2] Coelho M, Neves L, Sena-Cruz J. (2018). Designing NSM FRP systems in concrete using partial safety factors. Composites Part B Engineering 139: 12-23. https://doi.org/10.1016/j.compositesb.2017.11.031

[3] Li MM, Chen C, Mao J, Yang C, Li SL, Gao Y, Shen JS. (2018). Experimental research on the improvement effect of ECE treatment on durability of early concrete with chloride. Concrete 2018(1): 12-14. https://doi.org/10.3969/j.issn.1002-3550.2018.01.004

[4] Thomas RJ, Ariyachandra E, Lezama D. (2018). Comparison of chloride permeability methods for AlkaliActivated concrete. Construction \& Building Materials 165:104-111.

https://doi.org/10.1016/j.conbuildmat.2018.01.016

[5] Tuutti K. (1982). Corrosion of steel in concrete. Swedish Foundation for Concrete Research Stockholm 20(5): 105-119.

[6] Yu H, Himiob RJ, Hartt WH. (2007). Effects of reinforcement and coarse aggregates on chloride ingress into concrete and time-to-corrosion: Part 2-spatial distribution of coarse aggregates. Corrosion 63(9): 843849. https://doi.org/10.5006/1.3278310

[7] Yu H, Hartt WH. (2007). Effects of reinforcement and coarse aggregates on chloride ingress into concrete and time-to-corrosion: Part 1-spatial chloride distribution and implications. Corrosion 63(9): 843-849. https://doi.org/10.5006/1.3278434

[8] Hansen E, Saouma V. (1999). Numerical simulation of reinforced concrete deterioration-Part I: Chloride diffusion. ACI Materials Journal 96(2): 173-180.

[9] Wang Y, Li Q, Lin CA. (2015). Chloride diffusion analysis of concrete members considering depthdependent diffusion coefficients and effect of reinforcement presence. Journal of Materials in Civil Engineering 28(5): 04015183. https://doi.org/10.1061/(asce)mt.1943-5533.0001425 
[10] Oh BH. (2003). Chloride diffusion analysis of concrete structures considering effects of reinforcements. ACI $\begin{array}{llll}\text { Materials } & \text { Journal } & 100(2) \text { : }\end{array}$ https://doi.org/10.14359/12554

[11] Kranc SC, Sagues AA, Presuel-Moreno FJ. (2002). Decreased corrosion initiation time of steel in concrete due to reinforcing bar obstruction of diffusional flow. ACI Materials Journal 99(1): 51-53. https://doi.org/10.14359/11316

[12] Wang XL, Ma GS, Qi CL. (2010). Numerical simulation method for predicting chloride concentration distributing around reinforcement in concrete. Advanced Materials Research 163-167: 3138-3142 https://doi.org/10.4028/www.scientific.net/amr.163167.3138

[13] Yu H, Hartt WH. (2011). Correction of chloride threshold concentration and time-to-corrosion due to reinforcement presence. Materials and Corrosion 62(5): 423-430. https://doi.org/10.1002/maco.200905516

[14] Collepardi M, Marcialis A, Turriziani R. (1970). The kinetics of penetration of chloride ions into the concrete. II Cemento 67(1): 157-164.

[15] Collepardi M, Marcialis A, Turriziani R. (1972). Penetration of chloride ions into cement pastes and concretes. Journal of the American Ceramic Society 55(10): 534-535. https://doi.org/10.1111/j.11512916.1972.tb13424.x

[16] Mangat P, Limbachiya M. (1999). Effect of initial curing on chloride diffusion in concrete repair materials Cement and Concrete Research 29(9): 1475-1485. https://doi.org/10.1016/s0008-8846(99)00130-1

[17] Maage M, Helland S, Poulsen E, Vennesland Ø, Carlsen JE. (1996). Service life prediction of existing concrete structures exposed to marine environment. ACI $\begin{array}{llll}\text { Materials } & \text { Journal } & \text { 93(6): } & \text { 602-608 }\end{array}$ https://doi.org/10.14359/9866

[18] Thomas MD, Bamforth PB. (1999). Modelling chloride diffusion in concrete: effect of fly ash and slag. Cement and Concrete Research 29(4): 487-495.

[19] Amey SL, Johnson DA, Miltenberger MA, Farzam H. (1998). Predicting the service life of concrete marine structures. an environmental methodology. Structural Journal 95(2): 205-214. https://doi.org/10.14359/540

[20] Kassir MK, Ghosn M. (2002). Chloride-induced corrosion of reinforced concrete bridge decks. Cement and Concrete Research 32(1): 139-143. https://doi.org/10.1016/s0008-8846(01)00644-5

[21] Nilsson L, Massat M, Tang L. (1994). Effect of nonlinear chloride binding on the prediction of chloride penetration into concrete structures. ACI Special Publication 45(2): 469-486.

[22] Saito M, Ishimori H. (1995). Chloride permeability of concrete under static and repeated compressive loading. Cement and Concrete Research 19(4): 803-808. https://doi.org/10.1016/0008-8846(95)00070-s

[23] Lim C, Gowripalan N, Sirivivatnanon V. (2000). Microcracking and chloride permeability of concrete under uniaxial compression. Cement and Concrete Composites 22(5): 353-360. https://doi.org/10.1016/s0958-9465(00)00029-9

[24] Gowripalan N, Sirivivatnanon V, Lim C. (2000) Chloride diffusivity of concrete cracked in flexure. Cement and Concrete Research 30(5): 725-730. https://doi.org/10.1016/s0008-8846(00)00216-7
[25] Uji K, Matsuoka Y, Maruya T. (1990). Formulation of an equation for surface chloride content of concrete due to permeation of chloride. Elsevier Applied Science 36(5): 258-267.

[26] Taffesea WZ, Sistonen E. (2013). Service life prediction of repaired structures using concrete recasting method: state-of-the-art. Procedia Engineering 57(1): 1138-1144. https://doi.org/10.1016/j.proeng.2013.04.143

[27] Song HW, Shim HB, Petcherdchoo A, Park SK. (2009). Service life prediction of repaired concrete structures under chloride environment using finite difference method. Cement and concrete composites 31(2): 120-127. https://doi.org/10.1016/j.cemconcomp.2008.11.002

[28] Paulsson-Tralla J. (2001). Service life prediction of concrete bridge decks repaired with bonded concrete overlays. Materials and Structures 34(1): 34-41. https://doi.org/10.1617/13534

[29] Xi Y, Bazant ZP. (1999). Modeling chloride penetration in saturated concrete. Journal of Materials in Civil Engineering 11(1): 58-65.

[30] Weyers RE, Fitch M, Larsen E, Al-Qadi I, Chamberlin W, Hoffman P. (1994). Concrete bridge protection and rehabilitation: Chemical and physical techniques: Service life estimates. Concrete Bridges.

[31] Zhang Y, Sun W, Liu Z, Chen S. (2011). One and two dimensional chloride ion diffusion of fly ash concrete under flexural stress. Journal of Zhejiang University $\begin{array}{llll}\text { SCIENCE } & \text { A } & \text { 692-701. }\end{array}$ https://doi.org/10.1631/jzus.a1100006

[32] Yu H, Sun W, Yan L, Ma H. (2002). Study on prediction of concrete service life I-Theoretical model. Journal of the Chinese Ceramic Society 30(6): 686-690.

[33] Pigeon M, Garnier F, Pleau R, Aitcin P. (1993). Influence of drying on the chloride ion permeability of HPC. Concrete International 15(2): 65-69.

[34] Liu J, Xing F, Dong BQ, Ding Z, Ma HY. (2010). Diffusion of chloride ions into concrete in salt spray environment. Journal of Shenzhen University 27(2): 192198.

[35] Locke CE. (1983). Effect of impressed current on bond strength between steel rebar and concrete. Corrosion 83 .

[36] Bourguiba A, Ghorble E, Dhaoui W. (2015) Epoxy resin/recycled sand mortars' resistance to chloride ions diffusion. Concret Creep 10: 843-852. https://doi.org/10.1061/9780784479346.100

[37] Shekarchi M, Rafiee A, Layssi H. (2009). Long-term chloride diffusion in silica fume concrete in harsh marine climates. Cement and Concrete Composites 31(10): 769775. https://doi.org/10.1016/j.cemconcomp.2009.08.005

[38] Li G, Yang B, Guo C, Du J, Wu X. (2015). Time dependence and service life prediction of chloride resistance of concrete coatings. Construction and Building Materials 83: 19-25. https://doi.org/10.1016/j.conbuildmat.2015.03.003

[39] Farahani A, Taghaddos H, Shekarchi M. (2015). Prediction of long-term chloride diffusion in silica fume concrete in a marine environment. Cement and Concrete Composites 59: 10-17. https://doi.org/10.1016/j. cemconcomp.2015.03.006

[40] Yu HF, Sun W, Ma HY. (2002). Study on prediction of concrete service life II-model's examination and application. Journal of the Chinese Ceramic Society 30(6): 691-695. 